\title{
Rheological properties of the polymeric blends
}

\author{
Tatyana Matseevich ${ }^{1 *}$, Andrey Askadskii ${ }^{1}$ \\ ${ }^{1}$ Moscow State University of Civil Engineering, Yaroslavskoe sh. 26, Moscow, 129337 Russia
}

\begin{abstract}
The calculation scheme for storage modulus and loss modulus for compatible polymers as a function of the temperature, stress state, and composition has been suggested. The relations for calculation of the storage modulus at high frequency for polymer of any chemical structure containing carbon, hydrogen, and oxygen atoms are suggested. Calculation scheme allows evaluation both of the storage modulus and loss modulus for compatible blends of polymers. The calculations are performed for mixtures of polystyrene, poly(methyl methacrylate), polycarbonate, and polyethylene oxide used for the manufacture of building materials.
\end{abstract}

\section{Introduction}

Within the frame of the papers [1] it was shown that the storage modulus at high frequencies is described by the following equation

$$
G=\frac{\sum_{i} \Delta V_{i}}{\sum_{i} g_{i} \Delta V_{i}+\sum_{j} f_{j}},
$$

where $g_{i}=\frac{S_{i}}{k_{i} l_{i}}$; the values of $g_{i}$ characterize an average contribution of each atom into the value of $\frac{S_{i}}{k_{i} l_{i}} ; f_{i}$ is the selection of constants which characterize the influence of strong intermolecular interaction (dipole-dipole interaction, hydrogen bonds, etc.); $S_{i}$ is the Vander-Waals surface of the $i$-th atom, through which the intermolecular interaction occurs; $\kappa_{i}$ is the elasticity coefficient of the $i$-th atom bond; $l_{i}$ is the characteristic size of the bond; $\sum_{i} \Delta V_{i}$ is the Van-der-Waals volume of $i$-th atom entering into repeating unit of polymer.

For compatible blend of polymers the equation (1) is transformed to the form:

$$
G=\frac{\alpha_{1}\left(\sum_{i} \Delta V_{i}\right)_{1}+\alpha_{2}\left(\sum_{i} \Delta V_{i}\right)_{2}}{\alpha_{1}\left(\sum_{i} g_{i} \Delta V_{i}+\sum_{j} f_{j}\right)_{1}+\alpha_{2}\left(\sum_{i} g_{i} \Delta V_{i}+\sum_{j} f_{j}\right)_{2}},
$$

where $\alpha_{1}$ and $\alpha_{2}$ are the molar parts of polymer 1 and 2, respectively;

\footnotetext{
${ }^{*}$ Corresponding author: tmats@rambler.ru
} 
$\left(\sum_{i} g_{i} \Delta V_{i}+\sum_{j} f_{j}\right)_{1}$ and $\left(\sum_{i} g_{i} \Delta V_{i}+\sum_{j} f_{j}\right)_{2}$ are the selections of constants for the polymer 1 and 2 , respectively.

Taking into account that in accordance with the equation (1) the values of $\left(\sum_{i} g_{i} \Delta V_{i}+\sum_{j} f_{j}\right)$ is equal to $\left(\sum_{i} g_{i} \Delta V_{i}+\sum_{j} f_{j}\right)=\frac{\sum_{i} \Delta V_{i}}{G}$ we can rewrite the equation (2) as:

$$
G=\frac{\alpha_{1}\left(\sum_{i} \Delta V_{i}\right)_{1}+\alpha_{2}\left(\sum_{i} \Delta V_{i}\right)_{2}}{\alpha_{1} \frac{\left(\sum_{i} \Delta V_{i}\right)_{1}}{G_{1}}+\alpha_{2} \frac{\left(\sum_{i} \Delta V_{i}\right)_{2}}{G_{2}}},
$$

where $G_{1}$ and $G_{2}$ are the moduli of the component 1 and 2, respectively. Because $\alpha_{1}+\alpha_{2}=1$, obtain:

$$
G=\frac{\left(\sum_{i} \Delta V_{i}\right)_{1}+\alpha_{2}\left[\left(\sum_{i} \Delta V_{i}\right)_{2}-\left(\sum_{i} \Delta V_{i}\right)_{1}\right]}{\frac{\left(\sum_{i} \Delta V_{i}\right)_{1}}{G_{1}}+\alpha_{2}\left[\frac{\left(\sum_{i} \Delta V_{i}\right)_{2}}{G_{2}}-\frac{\left(\sum_{i} \Delta V_{i}\right)_{1}}{G_{2}}\right]} .
$$

The equation (4) allows description of the shear modulus $G$ depending on molar concentration of Polymer 2.

Let us examine the example of calculation using the polymers used in the building industry. It is well known that fully compatible blend of polymers is as following: "polystyrene + polycarbonate". The Table 1 of the values $g_{i}$ and $f_{j}$ is borrowed from the paper [1]:

Table 1. Values of constants $g_{i}$ and $f_{j}$

\begin{tabular}{|l|c|c|}
\hline $\begin{array}{c}\text { Atom or type of } \\
\text { intermolecular } \\
\text { interaction }\end{array}$ & \multicolumn{2}{|c|}{ Values of $g_{i}$ or $f_{j}$} \\
\hline Carbon & $g_{C}, \mathrm{~cm}^{2} / \mathrm{kg}$ & -1.277 \\
\hline Hydrogen & $g_{H}, \mathrm{~cm}^{2} / \mathrm{kg}$ & 4.376 \\
\hline Oxygen & $g_{O}, \mathrm{~cm}^{2} / \mathrm{kg}$ & 116.95 \\
\hline Double bond & $f_{\neq}, \AA^{3} \mathrm{~cm}^{2} / \mathrm{kg}$ & 30.925 \\
\hline $\begin{array}{l}\text { Dipole-dipole } \\
\text { interaction* }\end{array}$ & $f_{d}, \AA^{3} \mathrm{~cm}^{2} / \mathrm{kg}$ & 84.472 \\
\hline
\end{tabular}

* Parameter $f_{d}$ is introduced for each branching in the back bone or side chain. This parameter is introduced also in the presence of a polar group of any type.

Using these parameters as well as the Van-der-Waals volumes of the atoms [2-5] we obtain for polystyrene

$$
\left(\sum_{i} g_{i} \Delta V_{i}+\sum_{j} f_{j}\right)_{P S}=-1.277(13.1+8.7+8.4+5 \cdot 12.7)+4.376(8 \cdot 2.0)+84.472=34.8 \text {. Van-der- }
$$


Waals volume of Polystyrene is $\left(\sum_{i} \Delta V_{i}\right)_{P S}=110 \AA^{3}$ (calculations are produced by the software Cascade). So, the value of storage modulus is $G_{P S}=3.15 \mathrm{~kg} / \mathrm{cm}^{2}$ (it should be noted that the experimental value of $G=3.16 \mathrm{~kg} / \mathrm{cm}^{2}$ ).

For polycarbonate $\left(\sum_{i} g_{i} \Delta V_{i}+\sum_{j} f_{j}\right)_{P C}=-1.277(4 \cdot 16.9+6 \cdot 8.4+2 \cdot 11.6+4 \cdot 12.7+4.5+$ $+2 \cdot 12.7+19.0)+4.376(22 \cdot 2.0)+116.95(2 \cdot 2.7+5.95)+84.472=1285.3$. Van-der-Waals volume of polycarbonate is $\left(\sum_{i} \Delta V_{i}\right)_{P C}=305.3 \AA^{3}$. So, the value of storage modulus is $G_{P C}=0.24$ $\mathrm{kg} / \mathrm{cm}^{2}$. The dependence of storage modulus of the blend under consideration on the molar part of polycarbonate is shown on Figure 1.

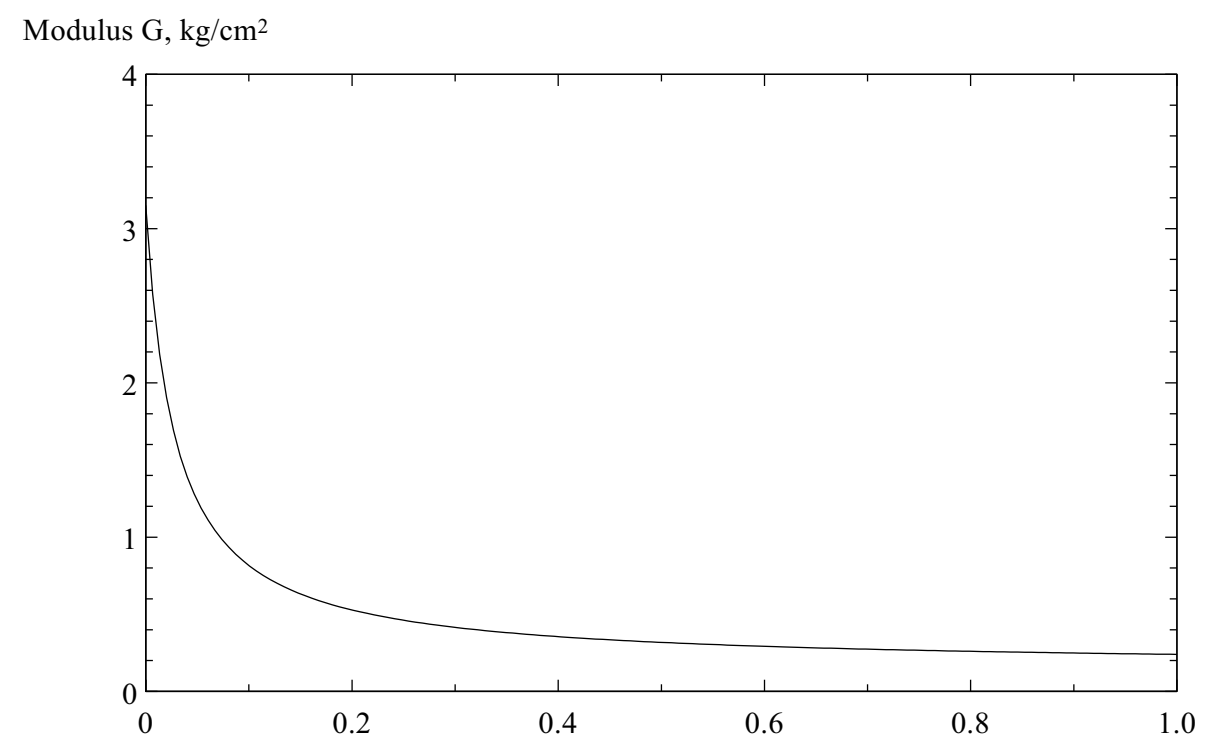

Molar part of Polycarbonate $\alpha \mathrm{PC}$

Fig.1. Dependence of storage modulus on the molar fraction of polycarbonate.

The major curvature of the dependence is due to the great difference between the Van-derWaals volumes of the components.

The other compatible blend is "poly(ethylene oxide) + poly(methyl methacrylate)". For poly(ethylene oxide) $\left(\sum_{i} g_{i} \Delta V_{i}+\sum_{j} f_{j}\right)_{P E O}=-1.277(2 \cdot 16.2)+4.376(4 \cdot 2.0)+116.95 \cdot 3.4=$ $=391.26 \mathrm{~cm}^{2} / \mathrm{kg} \cdot \AA^{3}$. Van-der-Waals volume of poly(ethylene oxide) $\left(\sum_{i} \Delta V_{i}\right)_{P E O}=43.7 \AA^{3}$. So, the value of storage modulus is $G_{P E O}=0.112 \mathrm{~kg} / \mathrm{cm}^{2}$. For poly(methyl methacrylate) $\left(\sum_{i} g_{i} \Delta V_{i}+\sum_{j} f_{j}\right)_{P M M A}=-1.277(13.1+5.0+17.2+15.9+20.3)+4.376(8 \cdot 2.0)+116.95(5.85+$ $+3.4)+84.472 \cdot 2=1229 \mathrm{~cm}^{2} / \mathrm{kg} \cdot \AA^{3}$. Van-der-Waals volume of poly(methyl methacrylate) 
$\left(\sum_{i} \Delta V_{i}\right)_{P M M A}=96.4 \AA^{3}$. So, the value of storage modulus is $G_{P M M A}=0.08 \mathrm{~kg} / \mathrm{cm}^{2}$.

The dependence of storage modulus of this blend on the molar part of poly(methyl methacrylate) is shown on Figure 2.

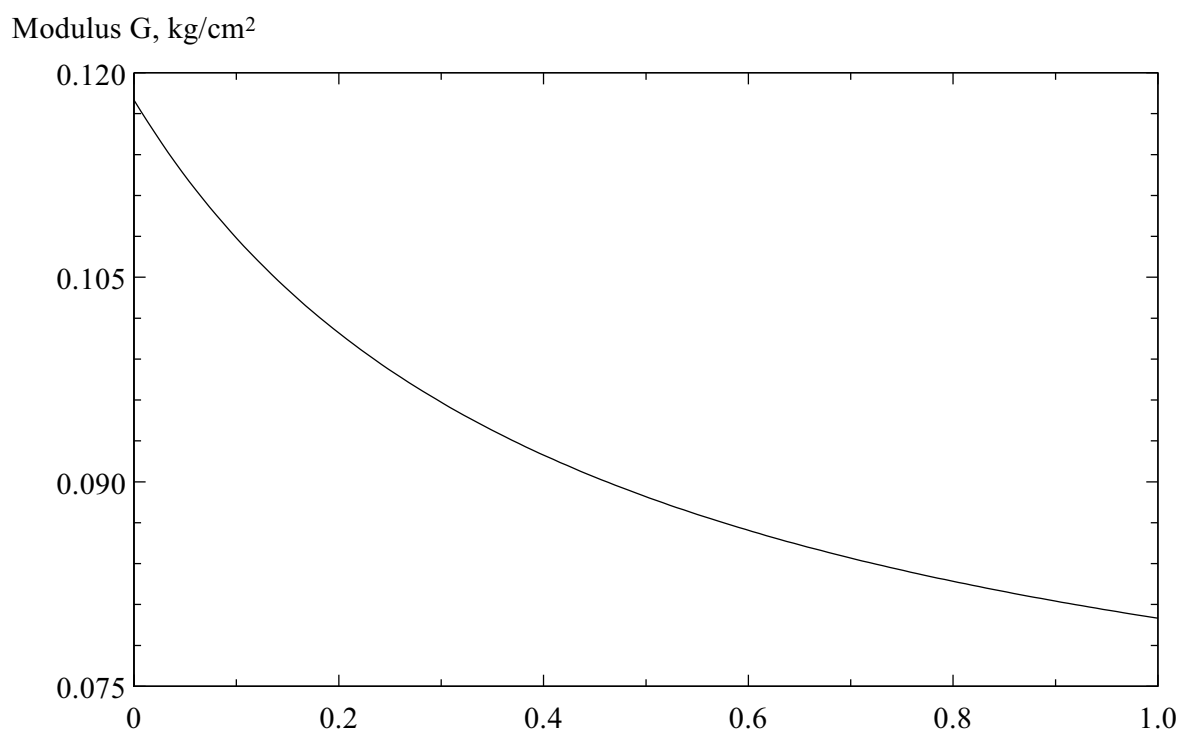

Molar part of Poly(methyl methacrylate), גPMMA

Fig.2. Dependence of storage modulus on the molar part of poly(methyl methacrylate)

It is well known that molar $\alpha_{m}$ and weight $\alpha_{w}$ fractions are related by

$$
\alpha_{m}=\frac{1}{1+\frac{M_{2}}{M_{1}}\left(\frac{1}{\alpha_{w}}-1\right)},
$$

where $M_{1}$ and $M_{2}$ are the molecular weights of the repeating units of polymer 1 and polymer 2 , respectively.

The dependence of the storage modulus on the weight part $\alpha_{w, 2}$ of the polymer 2 is described by the following formula

$$
G=\frac{\left(\sum_{i} \Delta V_{i}\right)_{1}+\frac{\left[\left(\sum_{i} \Delta V_{i}\right)_{2}-\left(\sum_{i} \Delta V_{i}\right)_{1}\right]}{1+\frac{M_{2}}{M_{1}}\left(\frac{1}{\alpha_{w, 2}}-1\right)}}{\frac{\left(\sum_{i} \Delta V_{i}\right)_{1}}{G_{1}}+\frac{\left[\frac{\left(\sum_{i} \Delta V_{i}\right)_{2}}{G_{2}}-\frac{\left(\sum_{i} \Delta V_{i}\right)_{1}}{G_{1}}\right]}{1+\frac{M_{2}}{M_{1}}\left(\frac{1}{\alpha_{w, 2}}-1\right)}} \cdot
$$

For poly(ethylene oxide) $M_{\mathrm{PEO}}=44.1$; for poly(methyl methacrylate) $M_{\mathrm{PMMA}}=100$; for polystyrene $M_{\mathrm{PS}}=104$; for polycarbonate $M_{\mathrm{PC}}=310$. Substituting all the physical 
parameters mentioned above obtain the dependence of storage modulus on the weight part of poly(methyl methacrylate) (Figure 3):

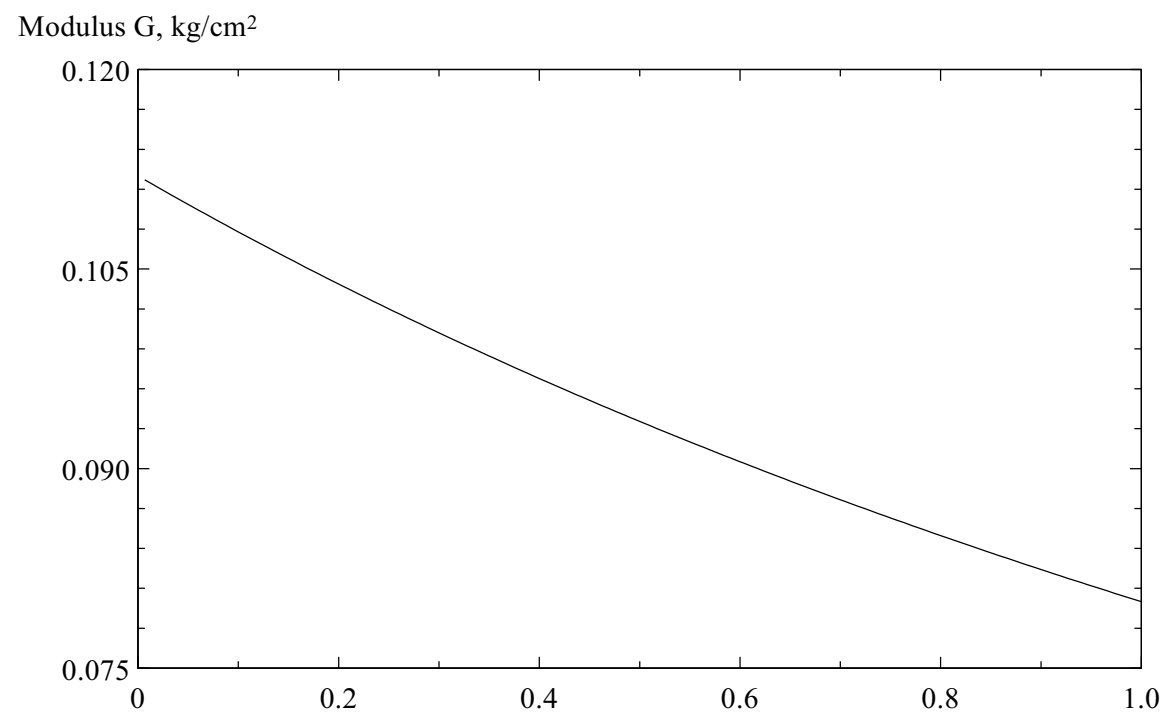

Weight part of Poly(methyl methacrylate), $\alpha_{\mathrm{w}, \mathrm{PMMA}}$

Fig.3. Dependence of storage modulus on the weight part of poly(methyl methacrylate).

The dependence of storage modulus on the weight part of polycarbonate is shown on Fig. 4.

Modulus $\mathrm{G}, \mathrm{kg} / \mathrm{cm}^{2}$

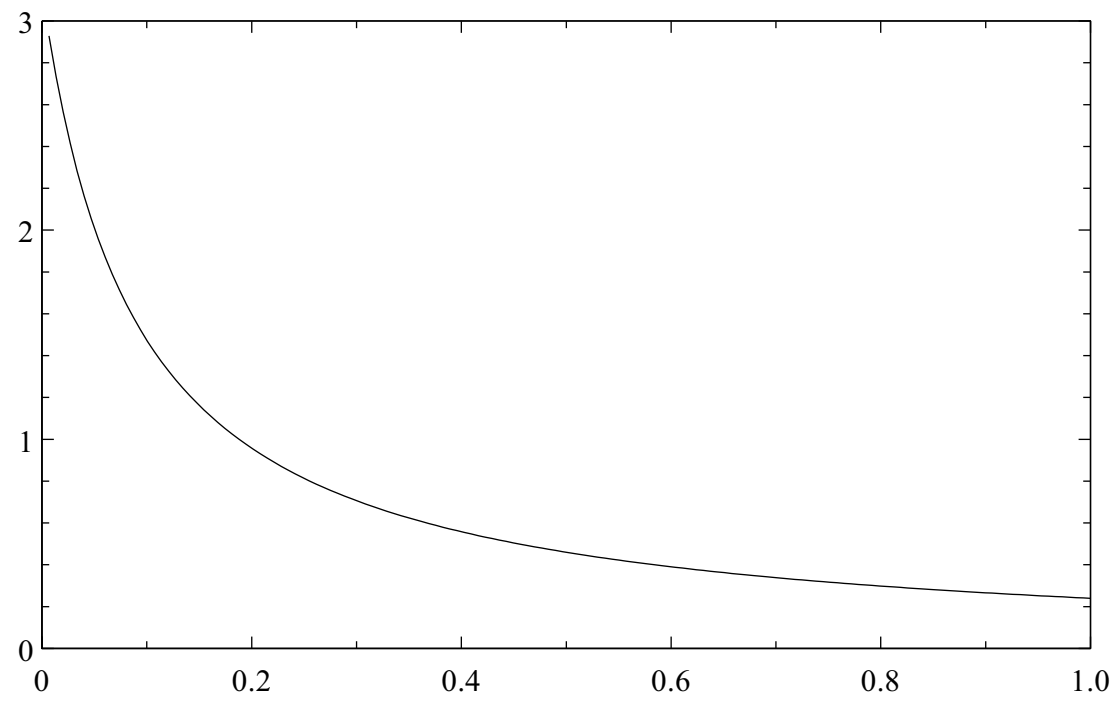

Weight part of Polycarbonate, $\alpha_{\mathrm{w}, \mathrm{PC}}$

Fig.4. Dependence of storage modulus on the weight part of polycarbonate $\alpha_{w, \mathrm{PC}}$. 


\section{The storage modulus and loss modulus of the polymer blends}

Now we consider the calculation of storage and loss moduli $G^{\prime}(\omega), G^{\prime \prime}(\omega)$ of the polymer blends. It is well-known that in the Maxwell regime (i.e., when there is a single typical relaxation time $\tau$ ) the storage an loss moduli are given by the following formulae

$$
\begin{aligned}
& G^{\prime}(\omega)=G \frac{(\omega \tau)^{2}}{1+(\omega \tau)^{2}}, \\
& G^{\prime \prime}(\omega)=G \frac{(\omega \tau)}{1+(\omega \tau)^{2}},
\end{aligned}
$$

where $G$ is the high-frequency limit of the storage modulus and the relaxation time $\tau$ is given by

$$
\tau=\frac{\eta}{G \Gamma\left(1+\frac{1}{k}\right)}
$$

where $\Gamma(x)$ is the Euler gamma function, and the parameter $k$ is due to the non-exponential relaxation in polymer systems.

As an example of calculations we consider a mixture of poly(ethylene oxide) and poly(methyl methacrylate). Using values $\left(\sum_{i} \Delta V_{i}\right)_{P M M A},\left(\sum_{i} \Delta V_{i}\right)_{P E O}, G_{P M M A}$, and $G_{P E O}$ for these polymers, the resulting dependencies on the concentration of PEO are given in Table 2 .

Table 2. The values of modulus $G$ for the compatible blends of PEO and PMMA.

\begin{tabular}{|c|c|c|}
\hline$\alpha_{P E O}, \%$ & $\alpha_{P M M A}, \%$ & $G, \mathrm{~N} / m^{2}$ \\
\hline 0 & 100 & 8000 \\
\hline 20 & 80 & 8240 \\
\hline 40 & 60 & 8570 \\
\hline 60 & 40 & 9050 \\
\hline 80 & 20 & 9810 \\
\hline 100 & 0 & 11200 \\
\hline
\end{tabular}

Viscosity of the mixtures calculated by Bicerano method [6] as a function of temperature is given in Table 3.

Consider first the temperature dependence of the storage and loss moduli. Assume, for definiteness, that $\alpha_{P E O}=40 \%, \alpha_{P M M A}=60 \%$, and the weight average molecular weight to be $M_{w}=40000 \mathrm{~g} / \mathrm{mol}$. Then the high frequency storage modulus is $G=8570 \mathrm{~N} / \mathrm{m}^{2}$ and the relaxation time as a function of temperature is given in the Table 3 .

Table 3. The values of $\eta_{\square}$ and $\tau$ at various temperatures.

\begin{tabular}{|l|c|c|c|c|c|c|}
\hline$T, K$ & 400 & 415 & 430 & 445 & 460 & 475 \\
\hline$\eta_{0}, \mathrm{~N} \cdot \mathrm{sec} / \mathrm{m}^{2}$ & 1387974 & 105633 & 283 & 147 & 79 & 45 \\
\hline$\tau, \mathrm{sec}$ & 81.0 & 6.16 & 0.0165 & 0.00855 & 0.00463 & 0.00262 \\
\hline
\end{tabular}

The corresponding frequency dependences both of the storage and loss moduli are presented in Figure 5. Storage moduli are plotted in full lines, and loss moduli are in dashed lines. 


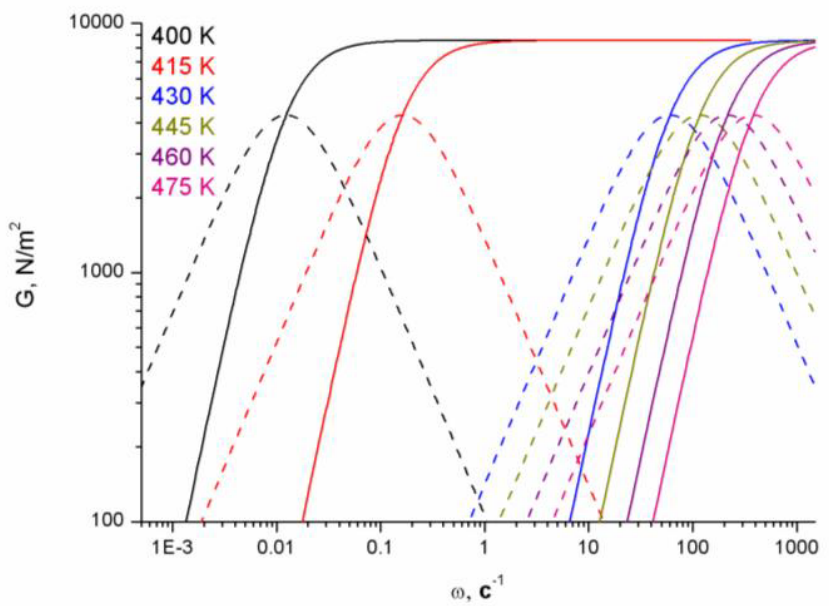

Fig.5. The dependencies of storage $\left(G^{\prime}\right)$ and loss moduli $\left(G^{\prime \prime}\right)$ on frequency at various temperatures.

To study the concentration dependence of the moduli, assume $T=445 \mathrm{~K}$, and, once again $M_{w}=40000 \mathrm{~g} / \mathrm{mol}$. Then, depending on the composition of the blend one has the following results for the high frequency storage modulus, the viscosity, and the relaxation time are given in Table 4.

Table 4. The values of $G, \eta_{0}$ and $\tau$ at various concentrations of the components.

\begin{tabular}{|l|c|c|c|c|c|c|}
\hline$\alpha_{P E O}, \%$ & 0 & 20 & 40 & 60 & 80 & 100 \\
\hline$G, \mathrm{~N} / \mathrm{m}^{2}$ & 8000 & 8240 & 8570 & 9050 & 9810 & 11200 \\
\hline$\eta_{0}, \mathrm{~N} \cdot \mathrm{sec} / \mathrm{m}^{2}$ & 130.4 & 125.0 & 146.5 & 245.8 & 447.7 & 419.3 \\
\hline$T, \mathrm{sec}$ & 0.00815 & 0.00758 & 0.00855 & 0.0136 & 0.0228 & 0.0187 \\
\hline
\end{tabular}

The corresponding frequency dependences of the storage and loss moduli are presented in Figures 6 and 7. Storage moduli are plotted in full lines, and loss moduli are in dashed lines.

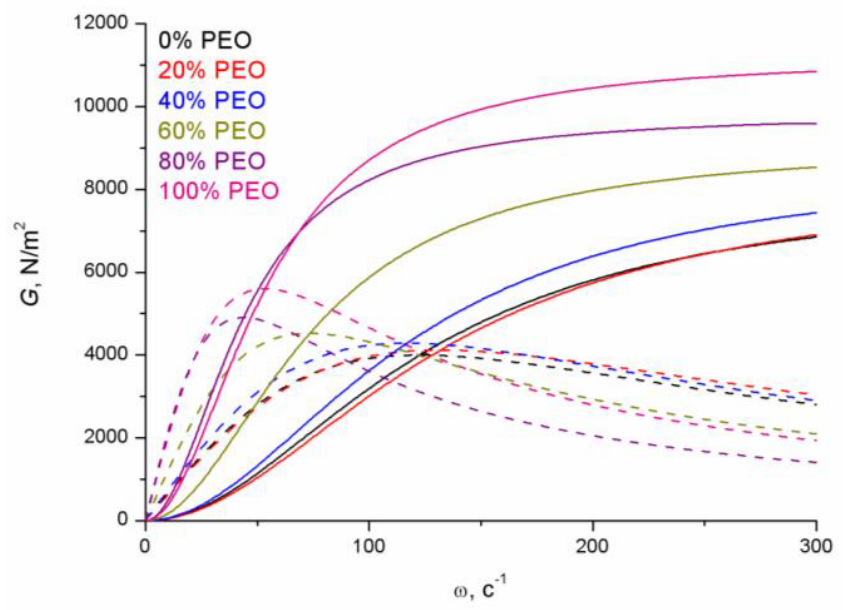

Fig.6. The dependencies of storage $\left(G^{\prime}\right)$ and loss moduli $(G$ ") on frequency at various contents of PEO. 


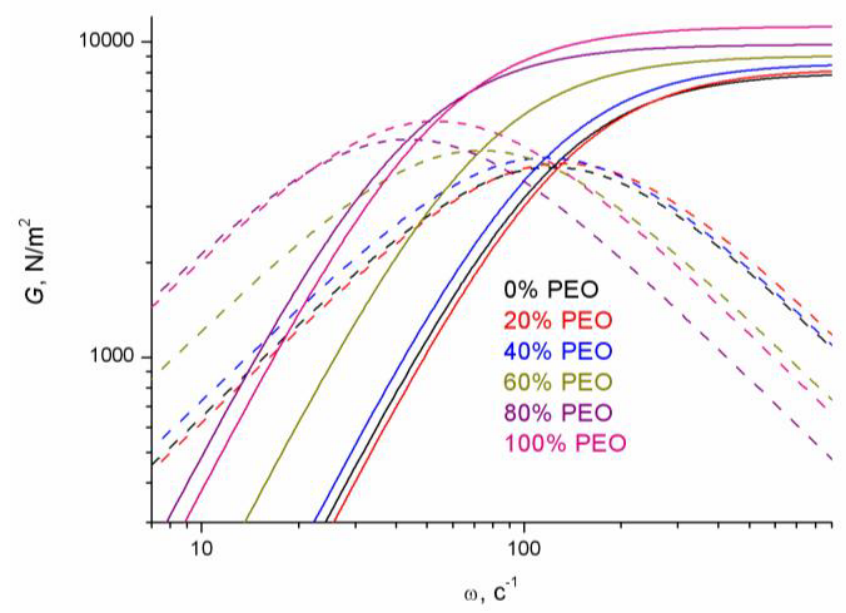

Fig.7.The dependencies of storage $\left(G^{\prime}\right)$ and loss moduli $\left(G^{\prime \prime}\right)$ on frequency at various contents of PEO.

\section{Conclusions}

The possibility of calculation of the modulus of elasticity at high frequency has been demonstrated. All the physical parameters we need for calculations can be predicted by the software Cascade (INEOS RAS). The dependencies of modulus of elasticity on both the molar and weight part possess various forms depending on the Van-der-Waals volume of the components. The proposed calculation scheme may be useful for predicting the rheological properties of polymeric materials and the search for optimal process conditions of production of building materials.

\section{References}

1. T. Matseevich, A. Askadskii, M. Popova, O. Serenko, S. Qi, Appl. Mech. Mater. (to be published).

2. 'A.A. Askadskiy, V.I. Kondrashenko, Computer Polymer Materials (Atomic and molecular level, Moscow, 1999)

3. A.A. Askadskii, Computational materials science of polymers (Cambridge International Silence Publishing, Cambridge, 2003)

4. A.A. Askadskii, A.P. Hohlov, Introduction to Physics and chemistry of polymers (Moscow, 2009)

5. A.A. Askadskii, M.N. Popova, V.I. Kondrashenko, Physical chemistry of polymeric materials and methods of their study (Moscow, 2015)

6. J. Bicerano, Prediction of Polymer Properties (Marcel Dekker Inc., New-York, 1996). 